\title{
Discussion on the Implementation of Immersion Bilingual Teaching in the Context of Sino-Foreign Cooperation in Running Schools
}

\author{
Chen Xueyan \\ Beihua University \\ Jilin, China \\ Email:455931074@qq.com
}

\author{
Wang Jihong* \\ Beihua University \\ Jilin, China \\ Email:22196595@qq.com \\ *Corresponding author
}

\begin{abstract}
To discussion the effectiveness of bilingual teaching in higher education in recent years. In Sino-foreign cooperation in running schools in undergraduates, immersion bilingual teaching has been vigorously popularized as a teaching mode for cultivating compound bilingual talents in colleges and universities. In this paper, the present situation of immersion bilingual teaching implemented in Sino-foreign cooperation in running schools in undergraduates is introduced, the achievements and problems in the immersion bilingual teaching mode currently are discussed, the essence and goal of bilingual teaching are explored, and some corresponding suggestions for the problems are proposed based on the analysis on the current situation of immersion bilingual teaching implemented in Sinoforeign cooperation in running schools in undergraduates. Provide some references for the improvement of the bilingual teaching quality of professional courses in undergraduates.
\end{abstract}

Keywords-Sino-foreign cooperation in running schools, Immersion bilingual teaching, Questionnaire survey

\section{INTRODUCTION}

In recent years, in the international education market, the mode of Sino-foreign cooperation in running schools in undergraduates has been developed rapidly. Diploma education is implemented in most undergraduate Sino-foreign cooperation education projects, that is, the students can get the education and degree certificates issued by two universities both the domestic university and foreign university at graduation, which is very popular with the big family. However, to get the diploma of foreign university is not easy. The undergraduate Sino-foreign cooperative education project requires that the courses that students learn at home must be recognized by the foreign cooperative institutions, or they must go to the foreign countries to continue their studies to obtain the relevant professional diploma after they learn their courses in China for a period of time, which requires that students must first pass through the language to reach a level that they can use the language as a tool to learn professional knowledge. Immersion bilingual teaching emphasizes the dual goal of improving the English level and gaining expertise through teaching in foreign language, so that this kind of teaching model has been early started and tried in Sino-foreign cooperative education projects. After more than ten years of practice, some experiences have been accumulated in undergraduate Sino-foreign cooperative education. Bilingual teaching has been tried in the country's colleges and universities one after another at present, and the investigation of bilingual teaching effectiveness has an important significance. This paper discusses the current situation, achievements, problems and suggestions of immersion bilingual teaching in the undergraduate Sino-foreign cooperation education to try to provide some reference for the bilingual teaching of other colleges and universities. Ease of Use

\section{CONCEPT AND CONNOTATION OF IMMERSION BILINGUAL TEACHING}

According to "Longman Dictionary of Applied Linguistics ", bilingual teaching refers to "the use of a second language in school for the teaching of content subjects", namely the use of a second or foreign language in schools for the teaching of various subjects. There are a variety of bilingual teaching models, including immersion, transition and maintenance etc. The so-called immersion refers that students are immersed in the second language environment all or half the time in schools, and the teachers not only teach the language knowledge of second language in the second language, but also some nonlanguage courses, that is to say, the second language is both the learning content and a tool that the students use to learn [1]. Immersion bilingual teaching originated from the "St Lambert test" in Monterey Park, Canada in 1960s, and the model succeeded greatly after that time, used for reference and promoted in the United States, Australia and other countries. In Canada, immersion bilingual teaching can be divided into three stages, early, middle and late, according to the starting time sooner or later, and two kinds, "partial immersion" and "total immersion" according to the proportion of second language use, the former refers to the second language proportion accounting for about $50 \%$ from beginning to end, and the latter refers to the second language proportion accounting for $100 \%$ at first, $80 \%$ two or three years later and $50 \%$ three or four year later [2]. Domestic studies have shown that the immersion bilingual teaching in Canada is greatly comparable with the bilingual teaching in China, with a highly referential significance for the bilingual teaching in China [3]. However, according to the actual situation of the undergraduate students' English level in China, the immersion bilingual teaching mentioned in this 
paper is different from the types of immersion bilingual teaching described above to some extent, referring to a process in which the proportion of foreign language used in the teaching is step by step and gradually increased.

\section{CURRENT SITUATIONS OF BILINGUAL TEACHING IN SINO- FOREIGN COOPERATIVE EDUCATION}

At present, immersion bilingual teaching is carried out in most undergraduate Sino-foreign cooperative education projects in different degrees, but there are differences in its implementation because of the different modes of cooperation. For example, students in some projects finish school for four years at home and a 2+2 mode is usually adopted in the schools, in which the immersion bilingual teaching of foreign language (English) subject is implemented in the first two years and the immersion bilingual teaching of professional subjects in the late two years. Students in some other projects learn their courses for a period of time at home and then continue to finish school abroad, and the school decides the courses and time proportion of immersion bilingual teaching according to the length of time when they study at home. But no matter what kind of modes, there is a common point, that is, "foreign language first, then majors, and gradually increased proportion of teaching in English”. Specifically, the immersion bilingual teaching of foreign language subject is conducted in the early stage, in which the language courses similar to those learned by students whose major is English are set, such as reading, writing, listening and speaking; the immersion bilingual teaching of professional courses is implemented in the middle and late stages, in which the professional courses are taught in foreign language partially or totally. Characteristics of the immersion bilingual teaching implemented in the undergraduate Sino-foreign cooperation education projects currently are primarily as follows: (1) Major. Most Sinoforeign cooperation undergraduate majors are business, information technology, and management, taking Shanghai as an example, where economy and management account for $53 \%$ [4], and the development of these fields in overseas is in advance of that at home and the sources of knowledge are almost from foreign language data; (2) courses. The colleges and universities that cooperate with foreign countries usually introduce part of the core courses at the same time when they use the design of the same foreign professional courses, including the teaching syllabus, teaching methods, textbooks and assessment methods, and they also ask foreign professors to demonstrate the teaching. The teaching of these courses has been more mature generally in the foreign countries, with a strong operability; (3) Teachers. The teachers for the cooperative education program tend to have the characteristics that "foreign language teachers and professional teachers, and Chinese teachers and foreign teachers, are paid equal attention to. In order to help the students improve their English level and adapt to the teaching requirements of professional courses by immersion bilingual teaching as soon as possible, language teachers with a strong ability are usually matched with the teaching and professional courses are often taught in a way that both Chinese and foreign teachers cooperate in the cooperative colleges and universities; at the same time, the teachers are also often dispatched abroad for their training; (4) Teaching materials. Version teaching textbooks simultaneously with the partners colleges are used in most of the courses and some domestic college English textbooks are also supplemented in language courses, such as the teaching materials for the reading courses; the version teaching textbooks for the professional courses are generally updated soon and rich in cases, but usually thicker; (5) Teaching means. During the immersion bilingual teaching, teachers generally pay more attention to the interaction between teachers and students, the group discussion, and the use of PPT and other teaching aids in the classroom.

\section{EFFECTIVENESS AND PROBLEMS OF IMMERSION BILINGUAL TEACHING IN UNDERGRADUATE SINO-FOREIGN COOPERATIVE EDUCATION}

\section{A. Effectiveness}

The students' English level has been greatly improved. The great improvement of the students' English level is the most remarkable effectiveness achieved in the implementation of immersion bilingual teaching through Sino-foreign cooperation in running schools. Due to the injection of vast language courses and the strengthening of their English ability in junior grades, and the integration of the concept of teaching in small classes and teaching by Chinese and foreign teachers teach together, the students can usually get rapid development in their English level in the first or the second grade through Sinoforeign cooperation in running schools. There were 32 articles in which "Sino foreign cooperative education" and "Bilingual Teaching" were used as the keywords in China HowNet from 1999 to 2008, of which 15 articles discussed the current situation and achievements of bilingual teaching, and 7 of them believed that the improvement of students' English performance was one of the significant gains. Through the bilingual teaching, 78.7\% of 2008 undergraduate double degree students at Sydney Industry and Commerce College of Shanghai University achieved IELTS $6 \sim 6.5$, and 15.1\% 7.0 7.5 in the second grade, which is not easy for non-English major students, indicating that the bilingual teaching can cultivate the students' international vision and promote the improvement of their comprehensive quality. The latest foreign textbooks are used, and the way taught cooperatively by Sinoforeign teachers or by foreign teachers alone is adopted in the immersion bilingual teaching of professional courses. Therefore, the students can be in contact with foreign professional knowledge, and at the same time, their international perspective can be exploited, their multicultural consciousness can be cultivated, their mind can be opened up, and their comprehensive quality can be improved, so that the students have shown a certain advantage in the job market. In 2008 double degree undergraduate students at Sydney Industry and Commerce College of Shanghai University, $75.4 \%$ of them believed that the immersion bilingual teaching could help "cultivate their international vision", which was the biggest harvest in the learning of their specialty; 30.2\% thought that their comprehensive quality was improved through the immersion bilingual teaching; 73.8\% considered that it was the immersion bilingual teaching that made them "have obvious advantages in employment. Chen $\mathrm{Li}$, Dong Su ${ }^{[5]}$ and Guo Xiaolin ${ }^{\text {[6] }}$ also pointed out that due to the special systems and bilingual teaching modes of Sino-foreign cooperation in running schools, the graduate students have strong the comprehensive quality and the employment market targeted. 


\section{B. Problems}

Shallow understanding of the professional knowledge. Although the students' English level has been greatly improved, this improvement is mainly reflected in the general social occasions, listening and speaking ability and professional reading ability according to the survey, while most students still feel difficult when they learn some profound professional knowledge in English in the classroom, leading to a shallow understanding of the professional knowledge. The reason is because on the one hand, the time for the professional courses is shortened due to the prolongation of time for the foreign language courses for the strengthening of foreign language ability in the mode of immersion bilingual teaching in the lower grades, on the other hand, the professional courses are taught partially in English, and even totally English explain, increasing the difficulty of understanding. Therefore, within the same time, the students can only learn relatively simple professional knowledge compared with the students who learn in native language Chinese, which has been discussed by Yang Xiaoming and Dong Shansheng ${ }^{[7]}$.

Lack of the knowledge in domestic professional fields. A little or little of the domestic professional situation is introduced in the English professional textbooks, so the students poorly understood the professional fields of professional disciplines in China, lack of the domestic professional knowledge. In addition, in the design of curriculum, the template from partners is directly uses, so there is no corresponding courses that introduce the domestic professional knowledge. Furthermore, there is a lack of the Chinese materials matching the English textbooks, causing some students to know only the English, but not know the corresponding expression in Chinese to that in English ${ }^{[8,9]}$.

Professional teaching quality to be improved. Many questionnaire studies have shown that the quality and effect of specialty teaching is the biggest problem existing in the immersion bilingual teaching. There are many factors that can affect the quality and effectiveness of teaching, such as the difficulty of curriculum, teachers, teaching materials, teaching methods, teaching environment, students' English level, which is closely related to teachers, teaching methods and students' English level. The implementation of bilingual teaching in China is not so long, the experience is not enough, and some conditions are relatively deficient, so how to improve the teaching quality and effect is a challenge for both teachers and students.

\section{DISCUSSION AND SUGGESTIONS ON THE IMPLEMENTATION OF IMMERSION BILINGUAL TEACHING IN SINO-FOREIGN COOPERATIVE EDUCATION}

\section{A. To make clear the essence and goal of bilingual teaching}

To solve the above problems in the bilingual teaching, first of all the essence and goal of bilingual teaching in China should be clarified. The essence of bilingual teaching colleges and universities in our country is to make students understand the professional knowledge when they improve their foreign level through the use of foreign language teaching ${ }^{[11]}$. In the stipulation of this essence, it is essential to understand the knowledge of their professional disciplines. Undergraduate
Sino-foreign cooperative education often attaches great importance to raising the level of foreign language because of the requirements of project courses, so that it takes great effort to solve the language problem, but virtually the process and depth of professional learning are ignored. Zhou $\mathrm{Li}^{[12]}$ pointed out that there were three levels of goals in bilingual teaching, namely subject knowledge goal, language goal and thinking goal. This paper argues that it is also applicable to undergraduates in Sino-foreign cooperative education project. The basic goal of immersion bilingual teaching implemented in Sino-foreign cooperation in running schools is to master the same knowledge of subjects as that taught in Chinese, the second goal is to improve the foreign language level and ability related to the development of the disciplines, and the final goal is to promote the development of bilingual thinking and comprehensive quality through the cultivation of international vision and cross-cultural awareness. Therefore, the relationship between the foreign language learning and professional learning should be clarified to improve the students' level of foreign language on the premise of not affecting the mastery of professional knowledge in the implementation of immersion bilingual teaching in the process of undergraduate Sino-foreign cooperative education.

\section{B. To keep the language advantage and improve the bilingual teaching quality of professional courses}

To sum up, the immersion bilingual teaching mode of undergraduate program of Sino-foreign cooperation in running schools has achieved good results in the improvement of students' foreign language level and overall quality, but the professional teaching still needs to be improved. The specific suggestions are as follows: (1) Curriculum time. The bilingual teaching of professional courses is a new try, so that the students need enough time to adapt to it. The author have found through multiple questionnaire investigations that regardless of differences in the level of English, most of the students are in favor of setting the introductory courses for the bilingual teaching of professional courses in the first year for extending the time for their professional learning to adapt to the bilingual teaching of professional courses as earlier as possible. The specific methods include setting up the language courses specifically targeting the professional learning, introducing the professional vocabularies, and understanding some simple professional articles; (2) Proportion of teaching in foreign language. From the perspective of the students' acceptance, the "degree" of proportion of professional course teaching in foreign language should be handled well. Based on the results from many surveys, the author believes that the proportion of teaching in English is supposed to be less than $50 \%$ during the early stage of professional course bilingual teaching and more than 70\% during the advanced stage; (3) Curriculum provision. Professional courses in bilingual teaching should be set up scientifically. The professional courses that are suitable for bilingual teaching should be selected and the opening time is chosen according to the difficulty of the courses. We do not insist on teaching some professional courses with strong theoretical characteristics in bilingual language, such as economy and courses with more mathematical models or icons, and our aim is always to ensure students to understand and grasp the basic professional knowledge; (4) Teaching materials. It is necessary for us to listen to the views of teachers and 
students, select the appropriate foreign original textbook or self-designed teaching materials, try to supplement with the notes for the key points and difficulties in Chinese, provide the auxiliary materials, and introduce the ways through which the students can contact the domestic professional knowledge; (5) Teachers. The schools should strengthen the training of bilingual teaching teachers and provide more overseas training opportunities. At the same time, not only the improvement of bilingual teachers in their foreign language ability is paid more attention to, but also their bilingual teaching ability in professional courses. For example, the teachers not only teach their students professional knowledge, but also supplement some foreign customs and cultural background, to cultivate students' multicultural consciousness; some small questions are assigned to students in each class to guide the students to learn independently; Teaching methods and effects. The schools should provide the corresponding teaching resources for the teachers, such as software: the universal foreign professional database, and hardware: projector, multimedia and classrooms. The establishment of the corresponding incentive systems can better mobilize the enthusiasm and creativity of teachers. Bilingual teaching requires teachers for skillfully converting between foreign language and Chinese to explain the professional knowledge for the students, which demands that the teachers have to put into their double time and energy for preparing lessons, so that the schools should set up a corresponding incentive policy; bilingual teaching requires not only the efforts of teachers, but also the guidance and support of school policies.

\section{SUMMARY}

More and more students and parents have accepted the immersion bilingual teaching mode which gradually improve the students' English application ability, and improve the overall comprehensive quality and professional development potential of teachers and students. But in bilingual teaching, we cannot ignore the foreign advanced concept of nursing, nursing culture infiltration, the teachers should strengthen the bilingual teaching in this respect, introduce the foreign culture into the foreign culture atmosphere, real fusion between eastern and western culture, let the advanced nursing concept into the real knowledge, solve the problem of the students' thinking ability, cultivating international nursing talents. Implementing bilingual teaching pattern of progressive penetration is according to the teaching object, teaching conditions, teaching content as well as by student's actual ability to accept information choice mode of bilingual teaching, bilingual teaching is efficient and practical mode, which can effectively solve students' adaptation problems in bilingual teaching and the shortage of bilingual teacher. The immersion bilingual teaching mode is conducive to the sustainable development of the bilingual teaching.

\section{REFERENCES}

[1] Qu bo. Immersive Bilingual Teaching Model and Internationalization of University Hotel Management. Journal of Peking University (philosophical social science edition), 2007, (5) : 256-258.

[2] Wang Hinghua. Bilingual Education and Bilingual Teaching. Shanghai: Shanghai Education, 2003:74.

[3] Yuan Pinghua, Yu Liming. Bilingual Education in Canada, Comparable to Chinese bilingual Education. Chinese University Teaching, 2005, (11) : 55-58.

[4] Gong Siyi. Research on the Model and Operation Mechanism of Chinese-foreign Cooperative Education. Shanghai university press, 2007:119.

[5] Chen li, Dong su. The Rules of Cooperation in Opening up are Strong. Introduction and Consultation, 2003, (4) : 34-35.

[6] Guo Xiaolin. "1-2-1" Chinese-foreign Cooperative Education Model and International General Talent Training. Journal of Sichuan normal university (social science edition), 2007, (5) : 101-105.

[7] Yang Xiaoming, Dong Shengshang. Chinese-foreign Cooperative Undergraduate Education and Teaching Mode of Study. Journal of modern university education, 2005, (2) : 79-79. 8

[8] Zhou Jie. Bilingual Teaching Mode of Chinese-foreign Cooperation run in Colleges and Universities to Explore. Journal of Liaoning Education Research, 2002, (5) : 52-53.

[9] Li Silan. Optimization of the Whole English Teaching Mode of Chineseforeign Cooperatively-run Schools [J]. Contemporary Education BBS, 2007, (7) : 28-29.

[10] Wei Dong, Wei Daming. Internationalization of Higher Education and Open Talent Cultivation. Journal of Chongqing Transport Institute (social science edition), 2003, (3) : 10-12.

[11] He Yang. The Essential Analysis of Bilingual Teaching in Chinese Universities. Journal of Xiangtan Normal University (social science edition), 2006, (1) : 138-139.

[12] Zhou li, Liu Qing, Xie Xiaofeng. A questionnaire survey on Bilingual Teaching in International Economics and Trade. Journal of Qiqihar University (philosophical social science edition),2007,56-59. 